\section{International Scientific Journal Theoretical \& Applied Science}

\author{
p-ISSN: 2308-4944 (print) e-ISSN: 2409-0085 (online) \\ Year: $2015 \quad$ Issue: 04 Volume: 24
}

Published: $30.04 .2015 \quad$ http://T-Science.org
Dilbar Tajimuratovna Khadjieva

Candidate of philological Sciences, associate Professor,

Karakalpak state University, Uzbekistan gulom82@yahoo.com

SECTION 29. Literature. Folklore. Translation

Studies.

\title{
THE INFINITIVE AS A CONSTRUCTIVE COMPONENT OF THE VERBAL PHRASE IN THE HISTORY OF ENGLISH LANGUAGE
}

\author{
Abstract: The article deals with the infinitive as a structural component of verbal phrases, \\ idiomatizational process of combination "shall + infinitive" in the history of English language. \\ Key words: infinitive, obligatory, idiomatization, verbal - objective construction, semantic-functional \\ characteristics. \\ Language: Russian \\ Citation: Khadjieva DT (2015) THE INFINITIVE AS A CONSTRUCTIVE COMPONENT OF THE \\ VERBAL PHRASE IN THE HISTORY OF ENGLISH LANGUAGE. ISJ Theoretical \& Applied Science 04 \\ (24): 142-144. \\ Soi: http://s-o-i.org/1.1/TAS*04(24)24 Doi: crossef http://dx.doi.org/10.15863/TAS.2015.04.24.24
}

\section{ИНФИНИТИВ КАК КОНСТРУКТИВНЫЙ КОМПОНЕНТ ГЛАГОЛЬНОГО СЛОВОСОЧЕТАНИЯ В СРЕДНЕАНГЛИЙСКОМ ЯЗЫКЕ}

Аннотация: В данной статье рассматривается инфинитив как конструктивный компонент глагольного словосочетания, процесс идиоматизации сочетания "shal+uнфинитив" и её вхождение в парадигму глагольного словоизменения в среднеанглийском языке .

Ключевые слова: инфинитив, долженствование, идиоматизация, глагольно-объектная конструкиия, сцеплённость, семантико- функичональные свойства.

Характер устойчивости функциональных связей в словосочетательных процессах среднеанглийского периода позволяет наметить два синхронных среза: конец XI-XIII века и XIII$\mathrm{XV}$ вв.

В раннесреднеанглийский период [по сравнению c древнеанглийском] произошли существенные изменения глагольно маркированной сочетаемости:

1) В функционально-вариантном ряду долженствования представлены с равной степенью узуальности формы: "shal [mot, ouh] + инфинитив".

Внутри ряда отмечается семантическое размежевание его составных членов в рамках общей функции долженствования.

Так, словосочетание “ouh+инфинитив" выражает значение “долженствование в силу морально-этических мотивов":

Ge owen penchen of god eueriche time [10, c. $25,21]$; as man ouh to donne $[10$, c. 28,12$]$
Словосочетание “mot+инфинитив" выражает “значение долженствование в силу вынужденных обстоятельств". Оно является неадекватной функцией данного синтаксического сочетания. При этом формальный контекст поддерживается наречиями типа nede, ned lunge: ...for pi euriche mon ham mot nede holden $[10$, c. 3,25$]$; ... .hwon ge nede mote speken $[10$, c. 3,25$] ; \ldots$ swerep pet he mot nede $[10$, c. 42,21$]$.

2) Форма настоящего времени уходит на периферию функционально-вариативного ряда будущего действия. Ведущим элементом функционально-вариативного ряда становятся лексические варианты модели модального содержания. При этом отсутствует здесь какаялибо семантическая дифференциация. Это подтверждает взаимозаменяемость в разных рукописях одного текста.

Ср.: в "Бруте" Лаямона:... ....pat we uncouthne mon to kinge wolleth haben $[11$, с. 550] и во второй рукописи: scullen haebben; 
“Описание жизни святой Юлианы”.... ".... leafdi quoth he leaf me ich the chulle seggen $[4$, c. 34$]$ и во второй рукописи:...lefdi quoth he lef me ant ich the wule seggen [4, c. 27]

K XIV в. функционально-вариативный ряд долженствования представлен двумя членами: "shal [moot] + инфинитив".

Сочетание "moot+инфинитив" имеет два значения: долженствование в силу 1) моральноэтических мотивов и 2) внешних обстоятельств. Причём второе значение лишь начинает входить в употребление.

Что касается словосочетания "shal+инфинитив", то оно является узуально ведущим в значении “долженствование в силу морально-этических мотивов”, а форма настоящего времени является окказиональным элементом функционально-вариативного ряда будущего действия. В связи с этим А.И.Смирницкий делает такое обобщение: "В среднеанглийском постепенно создаётся и аналитическая форма будущего времени. В древнеанглийском одним из основных средств отнесения действия к будущему была форма настоящего времени в сочетании с соответствующими обстоятельственными наречиями, выражающими будущность, то есть будущее выражалось чаще всего лексически. Правда, для выражения значения будущего в древнеанглийском иногда употреблялись и глаголы sculan “долженствовать” и willan “желать”, но эти глаголы, как правило, сохраняли своё собственное лексическое значение. В среднеанглийском глаголы shullen и willen всё чаще утрачивают лексическое значение и становятся лишь формальным показателем будущего времени. Но аналитическая форма в этот период ещё не изолировалась окончательно от соответствующих синтаксических словосочетаний’'[1, с. 123].

В любом случае сочетание “shall+инфинитив» занимает ведущее место в функционально-вариативном ряду будущего времени [2,с.480-481].

Ср. следующие подтверждения:

1. Перевод Тревизы "Polychronicon"сделан в XIV в. и содержит вставки неизвестного автора $\mathrm{XV}$ века. Латинская форма будущего времени регулярно передаётся словосочетанием "shall+инфинитив".

2. Кэкстан в "Dialogeues in French and English” передаёт французское будущее формой "shal+инфинитив" [will передаёт соответственно vouloir].

3. Об употребительности словосочетания "shal+инфинитив" в поздне-среднеанглийский период свидетельствует возможность употребления при shal предикатива, который выражается одним из лексических вариантов модели модального содержания.

Cp. подтвердительные контексты реализации:

1) Crisey de shal not con ne knowen me [3, c. 1404];

2) Manye thynges... which thou shalt not mowe suffre [3, c. 2656];

В развитии синтаксического сочетания "shall+инфинитив" знаменует новый этап. Процесс семантической вариативности внутри функционально-вариативного ряда “долженствования” заканчивается закреплением семантических расхождений. В итоге за "shall+инфинитив" закрепляется [в рамках общей функции долженствования] значение “персонифицированное” долженствование [8, с. 121-122] - необходимость выполнения действия, исходящая от говорящего.

Поскольку модальный фактор экстрасубъективен [9, с. 124], постольку вышеотмеченное значение реализуется лишь тогда, когда агент действия не совпадает с говорящим. Агент действия как объект долженствования представляется в высказывании эксплицитно. Субъект долженствования имплицитен: это говорящий. Отсюда данное значение реализуется лишь со вторым и третьим лицом субъекта, ибо для первого лица противопоставление агента действия и говорящего не релевантно. В свою очередь сочетание "shal+инфинитив" с первым лицом превращается в своеобразную идиому будущего времени.

Процесс идиоматизации сочетания "shal+инфинитив" и её вхождение в парадигму глагольного словоизменения связаны:

1) с семантическим размежеванием внутри функционально-вариативного ряда “желания” и соответственно с вхождением его в систему идиоматических форм,

2) c формальной дифференциацией в функционально-вариативном ряду будущего времени.

В результате этого два члена входят в парадигмальный ряд вместе как варианты одной и той же парадигматической словосочетательной единицы для разных контекстуальных окружений.

Инфинитив активно участвует в среднеанглийском языке при образовании других синтаксических оборотов. Отметим наиболее характерные из них.

Оборот с инфинитивом, выражающий условие:

To considre these wordes, one ought greatly to marveyle...[6, с. 350] [“Если учесть эти слова, то следует очень удивляться...”]. 
Impact Factor ISRA (India) $\quad=\mathbf{1 . 3 4 4}$

Impact Factor ISI (Dubai, UAE) $=\mathbf{0 . 8 2 9}$

based on International Citation Report (ICR)

Impact Factor GIF (Australia) $=\mathbf{0 . 3 5 6}$
Impact Factor JIF $\quad=\mathbf{1 . 5 0 0}$

Impact Factor SIS (USA) $\quad=0.912$

Impact Factor РИНЦ (Russia) $=\mathbf{0 . 1 7 9}$

Impact Factor ESJI (KZ) $\quad=\mathbf{1 . 0 4 2}$ c. 317]

Ye are grately to blame for to displease kyng [3,

[“Вас следует очень порицать за то, что вы доставили неудовольствие королю"].

Наибольшей частотностью употребления отличается оборот с инфинитивом, который имеет значение цели [Кстати, он был уже широко распространён и в древнеанглийском]:

...But prechith not, as freres don in leute to make us for our olde synnen wepe $[3$, c. 278] [...”Но не читает проповедей, подобно другим монахам в посту, чтобы заставить нас оплакивать старые грехи"];

Manie man,is frend fortomunen, made liknesseafter đewunen [2., с. 687] [“Многие люди, чтобы помнить своих друзей, делали, согласно обычаю, их изображения"].

Здесь инфинитив используется с forto. Однако он не вытеснил окончательно инфинитива c to. В среднеанглийском [особенно в позднесреднеанглийском] обе формы употребляются параллельно.

Так, Джефри Чосер употребляет инфинитив $\mathrm{c}$ to для выражения цели наряду с for и to:

The constable of the casteldoun is fare to seen this wrak [3, c. 512]

[“Дворецкий поспешил вниз к морю, чтобы посмотреть на разбитое судно”].

Таким образом развитие объектной конструкции с инфинитивом характеризуется в английском языке постепенно, медленным изменением, расширением, уточнением её применения на протяжении его многовекового существования. Расширение сферы применения объектной конструкции с инфинитивом в английском языке происходило путём развёртывания основных её элементов при сохранении исходного типа. Распространение глагольно-объектной конструкции не могло бы иметь места, если бы её структура противоречила общим внутренним законам, управляющим развитием и совершенствованием всего грамматического строя английского языка в целом. Дело в том, что в связи с распадом системы склонения и спряжения в английском языке грамматическая функция слова в большинстве случаев выявляется из контекста, и утраченные морфологические средства выражения различных грамматических значении восполняются за счёт синтаксических средств, а именно за счёт соответственного оформления словосочетаний.

Поэтому параллельно с разрушением флексии возрастает роль синтаксических словосочетаний и сцеплённость между их компонентами. Это и обусловливает широкое распространение, которое получают в английском языке предикативные обороты [в частности, объектная конструкция с инфинитивом]. При этом словосочетания отдельных типов различаются по распространённости в определённый период развития языка или же по степени проявления своих семантико-функциональных свойств.

\section{References:}

1. Smirnitskiy AI (1998) Lektsii po istorii angliyskogo yazyka (sredniy i novyy period). Moscow: Dobrosvet, "Knizhnyy Dom". Universitet, 1998. $-223 \mathrm{p}$.

2. (1957) Caedmons Genesis. Bibliothek der Angelsächsischen Poesie. Herausgegeben von C. W. M. Green. Goettingen, 1957. - 1708 p.

3. Chaucer G (1994) The Complete Works. Ed. by W. Skeat. Vols. I-VI. - Oxford, 1994-1995. 2880 p.

4. Juliana (1995) The Exeter Book. Ed. by Israel Gollenz. - London, 1995. - 719 p.

5. (1974) Lagamons brut or Chronicle of Britian. London, 1974. - 210 p.

6. Malary Morte Darth (1991) - Le MorteDarthur by Sir Thomas Malary.Ed. by H.O. Sommer. London, 1991. - 548 p.
7. Robins RH (2007) A Short History of Linguistics. - Bloomington: Indiana UP, 2007. $-308 \mathrm{p}$.

8. Stageberg NC (2008) An Introductory to English Grammar. New York etc.: Holt, Rinehart and Winston, 2008. - 548 p.

9. Strang, Barbara MH (2007) A History of English. - London: Methuan, 2007. - 568 p.

10. (1952) The Ancren Riwle. Ed. by J. Morton. London, 1952. $-600 \mathrm{p}$.

11. (2008) The Brut, or the Chronicle of England. Ed. by F. Brie. - London, 2008. - 740 p.

12. (1985) Caxt. Aym. - The Four Sons of Aymon. Ed. by O. Richardson. London, 1985. - 704 p. 